\title{
BIOLOGÍA E INNATISMO: ALGUNOS COMENTARIOS CRÍTICOS*
}

\author{
Claudia Lorena García \\ Instituto de Investigaciones Filosóficas \\ Universidad Nacional Autónoma de México \\ clga@servidor.unam.mx
}

RESUMEN: En el presente artículo argumento que algunos de los descubrimientos empíricos relativamente recientes en la biología del desarrollo nos llevan a abandonar ciertos conceptos de lo innato, en particular, aquellos que llamaremos 'internistas'. También examino la adecuación de tres caracterizaciones de lo innato propuestas recientemente que toman en cuenta los descubrimientos empíricos antes mencionados y pretenden recoger un núcleo importante de las connotaciones y afirmaciones asociadas a lo innato en algunas disciplinas empíricas. Además, argumento que dos de estas caracterizaciones son inadecuadas por razones diversas, y que es más plausible considerar la tercera como una explicación del concepto de un rasgo fenotípico heredado.

PALABRAS CLAVE: innato, herencia, biología del desarrollo, ciencias cognitivas

SUMMARY: In this paper I argue that some relatively recent empirical findings in developmental biology lead us to abandon some concepts of innateness, in particular those which we shall call 'internalist concepts'. I also examine three characterizations of innateness that have been recently proposed - characterizations which take into account those empirical findings and are attempts to explain some of the most important connotations and assertions associated to the word 'innate' as it is used in some empirical disciplines. It is also argued that two of these characterizations are inadequate for various reasons, and that it is more plausible to consider the third characterization as an explication of the concept of an inherited phenotypic trait.

KEY WORDS: innateness, inheritance, developmental biology, cognitive sciences

\section{Introducción}

En la bibliografía contemporánea en psicología, biología y otras ciencias naturales, se pueden encontrar varias nociones de lo

*Mi agradecimiento a Edna Suárez, Sergio Martínez y Maite Ezcurdia por sus comentarios iluminadores a algunas de las versiones anteriores de este artículo. 
innato que aparentemente forman una nebulosa familia de conceptos. La pregunta principal que intentaré responder en este artículo se refiere al impacto que algunos de los descubrimientos empíricos relativamente recientes en la biología del desarrollo y en la genética pueden tener en estos conceptos, particularmente, en los conceptos causales de lo innato - es decir, conceptos que caracterizan lo innato como aquello que resulta de cierto tipo de causas, o que tiene cierto tipo de efectos. Aquí argumentaré que estos descubrimientos nos llevan a abandonar algunos de estos conceptos, en particular aquellos que llamaremos 'internistas'. También examinaré la adecuación de algunas propuestas recientes para caracterizar lo innato que toman en cuenta los descubrimientos empíricos antes mencionados y que pretenden recoger un núcleo importante de las connotaciones y afirmaciones asociadas a lo innato en algunas disciplinas empíricas, especialmente en algunas áreas de las ciencias cognitivas.

\section{Nociones causales de lo innato}

Los conceptos de lo innato más importantes que encontramos en la bibliografía en psicología, biología y filosofía son causales. De hecho, por miles de años, los filósofos - y posteriormente los científicos- han defendido la tesis de que los seres humanos $\mathrm{u}$ otras criaturas tienen ciertos rasgos o capacidades que no podrían haber sido el resultado causal de la interacción de esas criaturas con sus medios ambientes "externos", sino que tuvieron que haber sido los resultados de sus propios recursos causales "internos". Así, la controversia entre los innatistas y sus oponentes gira tradicionalmente en torno a la pregunta de si cierto rasgo biológico, funcional, conductual o mental de un organismo está determinado causalmente y de manera exclusiva por factores que, en algún sentido, son "internos" al organismo, o si más bien tal rasgo está determinado también por algunos factores "externos". Llamaremos "innatistas internistas" a todos los que defienden la primera posición.

En lo que sigue, primero examinaré un par de innatismos internistas y enseguida argumentaré que, por las razones de corte empírico que presentaré, deben ser rechazados. Después 
estudiaré tres propuestas externistas para caracterizar lo innato, argumentando que dichas propuestas presentan serios problemas de adecuación a las maneras en las que la palabra 'innato' presuntamente se usa en la biología o en algunas ciencias cognitivas como la etología o la psicología del desarrollo, y propondré una de estas caracterizaciones más bien como una explicación del concepto de rasgo fenotípico heredado.

\subsection{Innatismo internista}

\subsubsection{Innatismo genético}

Un innatismo internista en el que la mayoría de la gente piensa de manera inmediata es el que llamaré 'innatismo genético'. Los innatistas de este tipo sostienen que algunos organismos poseen ciertos rasgos que están determinados exclusivamente por sus genes y que, por ende, son innatos. Sin embargo, esta creencia es claramente errónea: los genes por sí solos no pueden producir nada sin la ayuda de algunos factores denominados 'epigenéticos'; factores que abarcan desde las condiciones del ambiente intracelular y del ambiente extracelular, hasta la temperatura externa al organismo en desarrollo. ${ }^{1}$ Los factores epigenéticos - es decir, los no genéticos - siempre ejercen alguna influencia causal en el resultado final del desarrollo. Veamos esto un poco más a fondo.

La abrumadora mayoría de los organismos multicelulares muestran una forma de desarrollo que se conoce como 'desarrollo regulatorio' en el cual —en oposición a un desarrollo tipo mosaico que exhiben formas multicelulares más simplesalgunos genes regulan la "activación" o expresión de otros genes al producir ciertas proteínas que, a su vez, activan otros genes; éstos producen otras proteínas que activan otros genes, etc., con lo cual se forma un proceso muy complejo e interactivo (conocido como una 'cascada regulatoria') en el que el rasgo fenotípico resultante depende de la expresión, en un orden apropiado, de

${ }^{1}$ Como Hull lo ha dicho recientemente: “¿Acaso hay alguien que piense que los genes por sí mismos son suficientes para [producir] algo? [...] los deterministas genéticos son más notables por su ausencia" (Hull, 1999, p. 24; la traducción es mía). 
un gran número de genes. ${ }^{2}$ Adicionalmente, las proteínas que se encuentran en el ambiente extracelular con frecuencia interactúan con proteínas intracelulares para producir otras condiciones que tienen una influencia causal en el resultado final de la cascada regulatoria; es decir, el linaje de una célula y, en particular, el comportamiento de sus genes dependen de la historia causal de otras células. ${ }^{3}$ Así, los factores epigenéticos, tanto intracelulares como extracelulares, tienen una influencia causal en el resultado del desarrollo regulatorio.

Así, un innatista genético simple como el que he examinado en esta sección tendría que decir que nada es innato. Pero estoy de acuerdo con Wimsatt en que una noción de lo innato que tenga como consecuencia que todo $-\mathrm{o}$, alternativamente, que nada- es innato, debe rechazarse. Wimsatt dice:

Creo que no es muy controvertido afirmar que una buena estrategia definitoria para una distinción importante es que ninguna definición sea tal que no existan casos a los cuales se aplique cualquiera de los términos de la dicotomía. (Wimsatt, 1986, p. 190; la traducción es mía.)

\subsubsection{Innatismo interaccionista}

Recientemente, y dado que aquella forma simple de innatismo genético está claramente equivocada, un grupo de científicos cognitivos - Jeffrey Elman, Elizabeth Bates, Annette Karmiloff-Smith, Kim Plunkett y otros - intentaron salvar una noción de innatismo internista que fuera por lo menos prima facie plausible planteando una distinción de factores ambientales relevante al desarrollo ontogenético. Ellos propusieron que distinguiéramos entre aquellas interacciones de los genes con sus medios ambientes moleculares y celulares (es decir, sus interacciones "internas"), y otros tipos de interacciones, que llamaron "externas". Entre estas últimas, también diferenciaron dos tipos de interacciones: las que se dan entre el organismo

${ }^{2}$ Véase Elman et al. 1996, pp. 13-16.

${ }^{3}$ Véase Gerhart y Kirschner 1997, pp. 19 y 246. 
y su ambiente "individual", por una parte; y las que se producen entre ese organismo y el ambiente típico de la especie a la que pertenece. ${ }^{4}$ Así, para Elman, Bates y los otros, los factores "internos" incluyen todas y sólo aquellas interacciones de los genes del organismo con sus medios ambientes molecular y celular; mientras que el resto de los factores que intervienen en el desarrollo del organismo serán considerados como "externos". ${ }^{5}$ Una vez hechas estas distinciones, Elman et al. ofrecen la siguiente definición de lo innato:

el término innato hace referencia a los cambios que surgen como resultado de las interacciones que ocurren dentro del organismo mismo durante la ontogenia; es decir, las interacciones entre los genes y sus ambiente moleculares y celulares sin recurrir a información externa al organismo. (Elman, et al., 1996, p. 22; la traducción es mía.)

Además, aquellos rasgos que son resultado de la interacción del organismo con el ambiente "externo" típico de la especie a la cual pertenece se llamarán 'primales', mientras que los que surjan de la interacción del organismo con su ambiente individual se considerarán como el producto del "aprendizaje". La siguiente tabla resume estas distinciones y sus correspondencias: ${ }^{6}$

${ }^{4}$ La distinción que Elman y los otros proponen entre el ambiente individual y el típico de la especie es básicamente la distinción propuesta por Mark Johnson y John Morton, quienes distinguen entre el "ambiente típico de la especie" - es decir, aquellos aspectos del ambiente que son compartidos por todos los miembros de la especie - y el "ambiente específico del individuo" - a saber, las condiciones en el ambiente que sólo se dan para un organismo particular en desarrollo. Véase Johnson y Morton 1991, pp. 9 y ss. Más adelante veremos por qué la manera en que ellos hacen esta distinción tiene serios problemas.

${ }^{5}$ Nótese que tal como Elman et al. caracterizan esta distinción, no queda claro que sea exhaustiva de todos los factores causalmente relevantes para el desarrollo de muchos rasgos en un organismo: ¿cómo se clasificarán aquellos factores causalmente relevantes que no pertenecen ni a los genes ni a sus medios ambientes bioquímicos y celulares, y que no pertenecen tampoco al ambiente externo al organismo? ¿Son externos o internos? Hay una falta de claridad en sus planteamientos que nos impide encontrar una respuesta definida a estas preguntas.

${ }^{6}$ Reproduzco la tabla de Elman et al. 1996, p. 23. 


\begin{tabular}{lll}
\hline Nivel de interacción & Ambiente & Resultado \\
\hline molecular & interno & INNATO \\
celular & interno & INNATO \\
externo & típico de la especie & PRIMAL \\
externo & individual & APRENDIZAJE \\
\hline
\end{tabular}

Una pregunta que surge inmediatamente en relación con esta propuesta atañe a la manera en que debe caracterizarse el ambiente interno de un organismo; a saber, ¿qué tan "local", por así decirlo, debe ser un ambiente para que pueda ser considerado un ambiente "interno"? Y cualquiera que sea la respuesta a esta pregunta, siempre surgirá otra acerca de por qué "pintar la raya" ahí, y no en otra parte. Por ejemplo, supongamos que se dice que un ambiente bioquímico será considerado interno cuando consista únicamente en el estado actual de la célula que contiene el gen en cuestión. La pregunta inmediata es: ¿por qué no restringir esta caracterización de tal forma que sólo se incluya el estado actual del núcleo de la célula en cuestión?; o bien, ¿por qué no ampliarla e incluir también el estado de las células que rodean aquella célula, o parte del tejido del cual aquellas células son una parte, o el órgano del cual el tejido en cuestión es parte, etc.? - y, honestamente, no sé cómo puede haber una manera teóricamente interesante de responder estas preguntas. Más adelante daré algunas de las razones por las que pienso esto.

Para empezar, el problema de cómo hacer la distinción interno/externo (dónde "pintar la raya") de una manera interesante puede apreciarse si consideramos lo siguiente: supongamos que hemos decidido que el ambiente "celular" contiene únicamente aquellas condiciones que se encuentran en la juntura de una determinada célula $\mathrm{C}$ con el resto de las células con las cuales $\mathrm{C}$ está en contacto inmediato. El problema es que, en la mayoría de los organismos multicelulares, la comunicación intercelular es extensa; las células están íntimamente intercomunicadas de modo que lo que le sucede a una célula, y cómo se desarrolla, depende de lo que le sucede y le ha sucedido a muchas otras células, y no únicamente a las que están en contacto inmediato con aquélla; además, la comunicación intercelular involucra con 
frecuencia la expresión de ciertos genes. ${ }^{7}$ El punto es que no se puede suponer que lo que les pasa a, por ejemplo, cualesquiera de mis células está causalmente aislado de lo que les sucede o ha sucedido a cualesquiera de mis otras células.

Por otra parte, la caracterización de lo innato que Elman et al. proponen puede interpretarse de dos maneras distintas. Primero, ellos podrían querer decir que, para que un rasgo de un organismo sea innato, todas sus causas próximas o inmediatas tienen que ser internas (en su sentido), pero entonces tendrían que admitir que, por ejemplo, la adquisición de ciertos recuerdos o el aprendizaje de ciertas asociaciones son innatos, puesto que hay buenas razones para pensar que todas las causas inmediatas de estos procesos involucran exclusivamente factores internos ${ }^{8}-\mathrm{y}$ no creo que haya ningún innatista que esté dispuesto a afirmar que la formación de recuerdos específicos o el aprendizaje son innatos; de hecho, estos procesos han sido siempre el paradigma de lo que no es innato. ${ }^{9}$

Alternativamente, Elman et al. podrían querer decir que, para que un rasgo sea innato, todos sus antecedentes causales (no sólo sus causas "inmediatas" o "próximas") tienen que ser "internos" al organismo - es decir, todos sus antecedentes causales tienen que ser interacciones de los genes relevantes con sus medios ambientes moleculares o celulares-; pero entonces esta caracterización de lo innato resulta ser excesivamente estrecha puesto que hay buenas razones para pensar que los rasgos fenotípicos de un organismo con desarrollo regulatorio son el resultado de un complejo arreglo de muchos diferentes tipos de factores causales, entre los cuales se cuentan no sólo los medios ambientes intracelulares e intercelulares, sino también factores externos al organismo. Examinemos esto un poco más.

Mencioné antes que en las formas multicelulares complejas que tienen un desarrollo regulativo, tanto los medios ambien-

${ }^{7}$ Véase Gerhart y Kirschner 1997, loc. cit.

${ }^{8}$ Véase Kandel, Schwartz y Jessell 1995, pp. 674, 680 y 685.

${ }^{9}$ Además, según esta caracterización de lo innato, algunos tumores resultarían ser innatos puesto que todas sus causas inmediatas involucran exclusivamente la expresión de ciertos genes en ciertos ambientes moleculares y celulares. 
tes intracelulares como los intercelulares del gen o los genes en cuestión son causalmente relevantes en la determinación del curso del desarrollo ontogenético del organismo. Pero no sólo es esto; con frecuencia los factores que van más allá del ambiente intercelular tienen una influencia causal definitiva en el resultado del desarrollo; por ejemplo, en ciertas especies de tortugas el sexo no se determina al momento de la fertilización, sino por la temperatura de la arena en la cual se incuban los huevos - lo cual no quiere decir que la expresión de ciertos genes no esté involucrada también en la determinación del sexo de esas tortugas. Hay muchos ejemplos como éste que sugieren que el desarrollo regulativo involucra un número de factores, de los cuales sólo algunos pertenecen a la categoría de lo "interno" propuesta por Elman et al.

De hecho, actualmente no sabemos, en todos los casos de desarrollo regulatorio, si existen factores "externos" a los organismos en desarrollo - factores tales como la intensidad de la luz o la cantidad de gravedad a la cual está expuesto un embrión en una etapa temprana de su desarrollo, o la composición bioquímica del ambiente intrauterino- que afecten el resultado fenotípico final; es decir, no sabemos qué rasgos fenotípicos resultarían en los casos en los cuales tales factores fueran alterados, y cómo diferirían de los rasgos que surgen en un ambiente "normal". Por ejemplo, no sabemos bien a bien cómo es que ciertos cambios gravitacionales pueden afectar el desarrollo ontogenético en los vertebrados.

Sin embargo, existen buenas razones para pensar que es muy probable que, en el desarrollo ontogenético de tipo regulatorio, los factores "externos" ejerzan una influencia causal importante; esto es, que, normalmente, tales factores no sean simples disparadores causales de los procesos de desarrollo. ${ }^{10} \mathrm{La}$ estructura misma de estos procesos en la mayoría de los organismos multicelulares — que tienen la forma de redes complejas de cascadas regulatorias en las que los resultados fenotípicos últimos dependen de un número de factores causales genéticos y epigenéti-

${ }^{10}$ Por "disparador causal" entiendo un factor causal que determina únicamente el tiempo en el que ocurrirá su efecto. 
cos en un orden determinado - sugiere de manera convincente que es muy poco probable que haya casos en los cuales los factores epigenéticos "externos" no son importantes. ${ }^{11}$

El siguiente diagrama representa la estructura general del desarrollo regulatorio, y los tipos de factores que involucra:

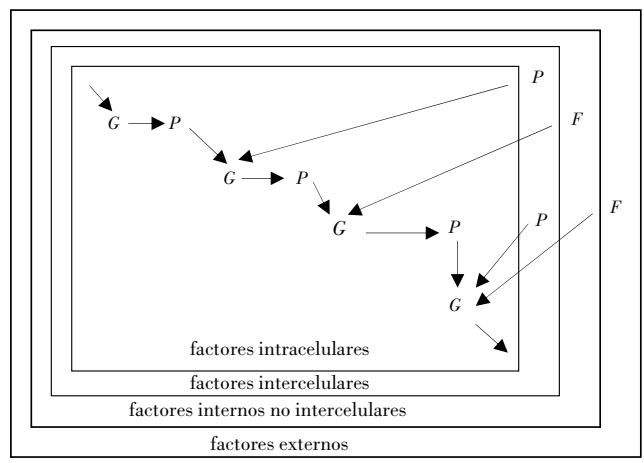

Diagrama que muestra la estructura de una cascada regulatoria. En este diagrama, $G$ es un gen, $P$ es una proteína (ya sea en el ambiente intracelular o intercelular), y $F$ es algún otro factor causal que interviene en la cascada regulatoria.

De todas las consideraciones anteriores surge el siguiente panorama general: los genes no "contienen" información fenotípica. No hay un sólo gen o grupo de genes que, por sí mismos, determinen que una criatura tenga ojos o dientes o inteligen-

${ }^{11}$ Además, nuestro genoma - y el genoma de muchas otras criaturasposee un gran número de genes "silenciosos"; es decir, genes que no llegan a expresarse y que normalmente no son parte de ninguna cascada regulatoria durante su desarrollo ontogenético. Sabemos, por ejemplo, que los pollos tienen un gen que, de expresarse (y dado un complejo arreglo causal) da como resultado en la aparición de dientes. Normalmente este gen no se expresa en los pollos; pero en ciertas condiciones creadas en el laboratorio, lo hace. La pregunta no es si tener dientes puede o no serles útil a los pollos de alguna manera (por ejemplo, funcionalmente), sino más bien si Elman et al. se inclinarían a llamar 'innata' a la aparición de esos dientes $-\mathrm{y}$, en todo caso, habría que explicar por qué. Si la respuesta es negativa, también habría que explicar por qué. A fin de cuentas, esos dientes son el resultado causal de factores genéticos. 
cia. Un rasgo fenotípico siempre es resultado de una compleja cascada regulatoria en la cual la expresión de un determinado gen produce ciertas proteínas, y activa así otros genes, etc., y de factores epigenéticos tanto internos como externos al organismo que intervienen en muchos niveles en este proceso; además, el orden en el que estos distintos factores causales ocurren es, por sí mismo, un factor causal crucial. Si el mismo gen, por ejemplo, apareciera en un orden diferente, o en combinación con otros genes o con otros factores epigenéticos, esto podría dar como resultado un rasgo fenotípico muy diferente. Así, en vista de lo que sabemos hasta ahora en la biología del desarrollo, si aceptásemos la caracterización de lo innato como aquello que es resultado de cascadas regulatorias que involucran únicamente factores epigenéticos "internos" — por ejemplo, sólo factores intercelulares-, entonces sería muy probable que ninguno de los rasgos fenotípicos de ningún organismo biológico de cierta complejidad (digamos, más complejo que el C. elegans) fuera innato - lo cual generaría una caracterización de lo innato que debería rechazarse por las razones antes mencionadas.

\subsection{Innatismos externistas}

Considerando las serias dificultades que tiene un innatismo internista, se podría intentar rescatar una noción de lo innato que tome en cuenta algunos de los descubrimientos acerca del desarrollo que se han bosquejado con anterioridad; en particular, que es probable que los rasgos biológicos en organismos de suficiente complejidad sean resultado de una variedad de factores causales, tanto internos como externos. Entre tales nociones externistas de lo innato, las más plausibles son aquellas que sostienen que un rasgo de un organismo $\mathrm{O}$ es innato cuando es el resultado causal de la expresión de uno o más genes $y$ de otros factores internos o externos que son típicos de la especie a la que $\mathrm{O}$ pertenece. Así, surge la pregunta acerca de qué factores pueden considerarse como parte del ambiente típico de la especie en cuestión. A continuación, en esta misma dirección, examinaré dos diferentes maneras de caracterizar lo innato. Posteriormente examinaré una propuesta sui generis de 
un innatismo externista que pretende señalar lo innato, no en términos de su historia causal durante el desarrollo ontogenético, sino en términos de sus efectos.

\section{2 .1 .}

Mark Johnson y John Morton propusieron una distinción entre el "ambiente típico de la especie" — es decir, aquellos aspectos del ambiente que son compartidos por todos los miembros de la especie - y el "ambiente específico del individuo" - a saber, las condiciones que son peculiares [unique] del ambiente en que vive un organismo particular. ${ }^{12}$ Así, para Johnson y Morton ciertos aspectos ambientales son "típicos de una especie" cuando todos los miembros de la especie comparten tales aspectos.

Sin embargo, la manera de hacer esta distinción es muy problemática. En primer lugar, un cambio muy pequeño en un aspecto ambiental $A$ en relación con solo uno o dos de los miembros de la especie $S$ sería suficiente para que $A$ se convirtiera en un aspecto ambiental específico del individuo, aun cuando el resto de los miembros de $S$ compartiesen $A$. Además, puesto que con frecuencia ocurren cambios ambientales pequeños y grandes, la caracterización de un ambiente típico de la especie propuesta por Johnson y Morton tendría como resultado que muy pocos aspectos ambientales serían típicos de alguna especie (quizá ninguno). Este problema tendería a desaparecer conforme fuéramos caracterizando los "aspectos del ambiente" de maneras cada vez más generales, puesto que, cuanto mayor sea la generalidad con que se concibe un determinado aspecto ambiental $A$, menor será el número de cambios en la variable ambiental correspondiente que cuenten como cambios de $A$ a no $A$. Sin embargo, esto tiene todos los visos de una respuesta ad hoc que, además, corre el riesgo de toparse con que sólo haya

${ }^{12}$ Véase Johnson y Morton 1991, loc. cit. Como vimos antes, Elman et al. proponen una caracterización muy similar de la noción de un ambiente típico de una especie, pero no la usan en una caracterización de lo que es innato a un organismo, sino más bien en la caracterización de lo que ellos llaman 'primal'. 
uno o dos ambientes distintos que sean típicos de la mayoría de las especies biológicas.

\section{2 .2 .}

Un acercamiento diferente a la noción de rasgo fenotípico innato consistiría en conceptuar tal rasgo (en un organismo) como el producto - adaptativamente ventajoso - de una serie de recursos causales, tanto internos como externos a ese organismo, que son sustancialmente parecidos a aquellos factores causales que originalmente dieron lugar a ese rasgo en algunos de sus ancestros. De hecho, en varias disciplinas empíricas - notoriamente, en algunas disciplinas cognitivas - existe la necesidad de un concepto que permita distinguir entre, por ejemplo, tener una capacidad de memoria o de aprendizaje, y tener algunos recuerdos particulares o haber aprendido una determinada canción. $\mathrm{Y}$ creo que lo que se tiene en mente aquí puede recogerse por medio de una distinción entre aquellos rasgos de los organismos que se desarrollan en ambientes (tanto "internos" como "externos") relevantes desde un punto de vista evolutivo, y aquellos que no lo son. Para ser más precisos, consideremos la siguiente situación:

En un tiempo $t$, hay un número $n$ de poblaciones distintas $P_{1}, \ldots, P_{n}$ de miembros de una especie $S$. Supongamos que una de estas poblaciones, $P_{i}(i=1, \ldots, n)$, vivió en algún tiempo anterior, $t$-e, en un ambiente $E_{i}$ que tenía un aspecto que constituía un problema adaptativo para los miembros de $P_{i}$, un problema para el cual tener un rasgo $T$ era una "solución", y que los miembros de $P_{i}$ que tenían $T$ y que vivieron en $E_{i}$ en $t$-e tenían mejores tasas de sobrevivencia y reproducción que aquellos que vivieron en $E_{i}$ pero que no tenían $T$ en $t$-e. En este caso, diremos que todos los factores causales ambientales ("internos" y "externos") $)^{13}$ responsables de la aparición de $T$ en los

${ }^{13}$ Nótese que uso "factor o condición o aspecto ambiental" en un sentido muy amplio que incluye básicamente a cualquier factor causal no genético responsable de la aparición de un rasgo fenotípico durante el desarrollo ontogenético. 
miembros de $P_{i}$ en $t$-e son típicos de la población $P_{i}$ con respecto al rasgo $T$ en $t$.

Una vez en posesión de esta idea, se podría proponer la siguiente caracterización de una noción externista de lo innato:

Un rasgo $T$ de un organismo perteneciente a una población determinada de una especie es innato en ese organismo en un tiempo $t$ cuando:

a) El organismo en cuestión posee $T$ en $t, \mathrm{y}$

b) $T$ apareció en ese organismo como resultado de su desarrollo ontogenético en un ambiente que incluye todos los factores causales ambientales típicos de esa población con respecto al rasgo $T$ en $t$, y como resultado de factores genéticos. $^{14}$

Nótese que esta caracterización de un factor ambiental típico de una población de una especie no requiere - como Johnson y Morton lo expresaban - que todos los miembros de la especie tengan que compartir un aspecto ambiental para que ese aspecto pueda ser parte del ambiente típico de esa población. Además, esta noción de lo innato no exige que un rasgo que es innato en un individuo de una población tenga que ser compartido por todos o por la mayoría de los miembros de esa población. ${ }^{15}$ Por otra parte, la fijación de un recuerdo particular probablemente

${ }^{14}$ Por ciertas razones que enunciaré más adelante, pienso que es mejor considerar esta caracterización como una aproximación a la noción de rasgo heredado, más que a la de rasgo innato.

${ }^{15}$ Es notorio también que, de acuerdo con esta noción de lo innato, la aparición de dientes en un pollo que se desarrolla en un laboratorio no sería innata (aun cuando la aparición de esos dientes se haya debido en parte a factores genéticos); mientras que los ojos negros en los humanos serían innatos sólo si la aparición de ese color de ojos en ciertos humanos les diera una ventaja evolutiva (en las condiciones ambientales en las que ellos vivían) y, además, ese color de ojos aparece ahora en los humanos como resultado de factores genéticos en las condiciones ambientales relevantes - y es probable que estas dos condiciones se cumplan. 
no haya dado a los humanos una ventaja evolutiva ${ }^{16}$-aunque la capacidad general para recordar muy probablemente sí, en cuyo caso esta capacidad general sería innata si su aparición en los humanos se debiera a factores genéticos en ciertas condiciones ambientales "típicas". 17

Aunque esta caracterización de lo innato promete aproximarse a algunas de las connotaciones asociadas a lo innato en algunas disciplinas empíricas, llamar 'innato' en este sentido a un rasgo de un organismo no implica nada con respecto a si los factores causales involucrados en la aparición de ese rasgo son todos "internos" a ese organismo, o si algunos son "externos". Grosso modo, en este sentido son innatos simplemente aquellos rasgos que han tenido un valor evolutivo específico para los miembros de una población, y que tienen un componente genético - algo que, a mi parecer, se acerca más a la noción de un rasgo fenotípico heredado que a la de lo innato, ya que la idea central que intenta recoger la caracterización de lo innato antes propuesta es que son innatos aquellos rasgos que tienen una determinada historia evolutiva en una población - en particular aquellos rasgos, que fueron seleccionados naturalmente, y que continúan apareciendo en tal población debido a la replicación sucesiva de una red de recursos causales tanto internos como ex-

${ }^{16}$ Ésta es una de las razones por las cuales, de acuerdo con esta caracterización de lo innato, la fijación de recuerdos particulares no cuenta como innata aun cuando - como mencionamos antes - existan razones para pensar que tal fijación requiere una expresión genética. Otra razón por la cual la fijación de un recuerdo particular no contaría como innata en un humano es que ésta requiere factores causales externos no típicos de alguna población humana - por ejemplo, un estímulo sensorial específico.

${ }^{17}$ Puesto que, en este sentido, lo innato es relativo a una población, si un organismo individual se incorporara a una población distinta de la misma especie (una población que, por ejemplo, evolucionó en un ambiente apropiadamente distinto), es posible que los rasgos de ese organismo que antes eran innatos, ya no lo sean ahora, o viceversa. Esto se debe a que el que un rasgo sea o no innato, de acuerdo con esta caracterización, está determinado por la historia evolutiva de la población a la cual el organismo en cuestión pertenece. Esta consecuencia indeseable puede evitarse si ajustamos nuestra manera de entender lo que significa que un organismo pertenezca a una determinada población — por ejemplo, imponiendo ciertos requisitos filogenéticos a la pertenencia a una población 
ternos a los miembros de esa población. ${ }^{18}$ Sin embargo, cuando la mayoría de la gente - incluidos los científicos cognitivosusa la palabra "innato", implícita e inadvertidamente importa ciertas connotaciones causales internistas muy fuertes. Existe entonces un riesgo palpable de que al usar la palabra "innato" para connotar aquellos rasgos con un "componente genético" que tienen cierto valor evolutivo, se infiera erróneamente que un rasgo tal debe ser el resultado exclusivamente de factores causales "internos" — una conclusión inaceptable. Por ejemplo, Elsa Newport, a todas luces psicóloga del desarrollo, tiende a colapsar lo innato y lo interno, como puede apreciarse en la siguiente cita:

Me concentro en evidencia de otro tipo a favor de las limitaciones innatas sobre el aprendizaje [...]. En particular, describo evidencia a partir de nuestro propio trabajo relativo a la adquisición del lenguaje humano, comparando miembros de la misma especie que difieren en los periodos de maduración durante los cuales están expuestos a ambientes de aprendizaje. [...] estos grupos de sujetos de nuestros experimentos aprenden el lenguaje de maneras muy distintas, lo que sugiere que, al igual que los gorriones, [los sujetos] entran en las situaciones de aprendizaje con limitaciones internas muy diferentes. En este caso, la evidencia a favor de las limitaciones innatas o biológicas proviene del hallazgo de que, a medida que estas limitaciones aparentemente desaparecen o se debilitan con la maduración, la habilidad para aprender declina. (Newport, 1991, p. 111; la traducción es mía.)

Tooby y Cosmides, un par de psicólogos evolucionistas, a veces también hacen afirmaciones que sugieren totalmente una concepción internista de lo innato, por ejemplo: "Toda teoría

${ }^{18}$ Para usar la terminología de "procesos de desarrollo" [developmental processes] que emplean, por ejemplo, Griffiths y Gray, podemos decir que un rasgo innato es un resultado de recursos (genéticos y epigenéticos), todos los cuales son parte del proceso de desarrollo, y "el proceso de desarrollo consiste en una serie de interacciones con los recursos del desarrollo que manifiesta una recurrencia apropiadamente estable en el linaje" (Griffiths y Gray, 1994, p. 292; la traducción es mía). 
psicológica coherente tiene en su base procedimientos o mecanismos innatos [...]. Decir que tales procedimientos son innatos significa que están especificados en la dotación [endowment] genética del organismo" (Tooby y Cosmides, 1990, p. 22; la traducción es mía).

Por esta razón - porque nuestro concepto de lo innato se inclina, en ocasiones imperceptiblemente, hacia connotaciones internistas - muchos científicos, tanto biólogos como psicólogos, piensan que es mejor descartar del todo la palabra 'innato'. Según la etóloga Sara Shettleworth, por ejemplo, el término 'innato" "dejó de usarse [en la etología] a medida que todos los involucrados en el debate sobre el término aceptaron que tanto los factores ambientales como los genéticos intervienen en todas las conductas" (Shettleworth, 1998, p. 191; la traducción es mía). La idea es que las connotaciones internistas parecen ser tan cruciales al concepto de lo innato que, una vez que se ha mostrado que tales connotaciones son empíricamente implausibles, el concepto mismo de lo innato tiene que ser abandonado. De hecho, en ningún texto de biología aparece ya la palabra 'innato'.

En la siguiente sección regresaremos a esta discusión cuando examinemos la propuesta de Wimsatt, quien considera innatos aquellos rasgos que son factores causales en el desarrollo de otros rasgos que han sido evolutivamente ventajosos.

\section{2 .3 .}

En su "Developmental Constraints, Generative Entrenchment, and the Innate-Acquired Distinction", ${ }^{19}$ Wimsatt propone la siguiente caracterización de lo innato en términos de su noción de atrincheramiento generativo (ésta es una primera aproximación):

Un rasgo $T$ de un organismo $O$ de la especie $S$ es innato en $O$ si y sólo si $T$ está generativamente atrincherado en $O$.

Intuitivamente, la idea es que un rasgo innato desempeña un papel causal importante en la generación de muchos otros rasgos

${ }^{19}$ Wimsatt 1986. 
de $O$ (durante su desarrollo ontogenético), rasgos que han probado tener importantes ventajas evolutivas. El rasgo, entonces, está "atrincherado" en el sentido de que es muy probable que un cambio - o su desaparición - tendría consecuencias causales muy serias para el desarrollo ontogenético de $O$. De hecho cuanto más sistémicas fuesen estas consecuencias, más atrincherado estará dicho rasgo.

Ahora bien, Wimsatt introduce su noción de atrincheramiento generativo usando una analogía entre, por una parte, la estructura general de ciertos procesos de desarrollo y de ciertos procesos evolutivos y, por otra, el modo de operación de lo que llama la "cerradura del desarrollo" [developmental lock], que consiste de una serie de diez ruedas giratorias, cada una de las cuales contiene en su superficie los números del 1 al 10. La cerradura se puede abrir cuando ciertas combinaciones de números logran alinearse al girar las ruedas. Una vez que se ha encontrado el número correcto para cada rueda, ésta hará "clic". Ahora bien, la posición correcta para cada rueda dependerá de las posiciones (correctas o no) de todas las demás ruedas que se encuentran a su izquierda, de modo que si alguna rueda se gira al azar, esto cambia las combinaciones correctas para todas las ruedas que se encuentran a su derecha. Así, si se trata de encontrar alguna de las combinaciones correctas para toda la cerradura girando las ruedas de izquierda a derecha —empezando por la que está a la extrema izquierda-, entonces la cerradura funcionará de manera muy simple. Después de cinco intentos, se encontrará la solución para la rueda situada en la extrema izquierda, y lo mismo sucederá con la siguiente rueda, y la siguiente, etc., de modo que la probabilidad de que, al proceder así, cualquier movimiento de cualquier rueda sea parte de la solución correcta para toda la cerradura es de $1 / 50$. Por otra parte, si se intenta encontrar alguna de las combinaciones correctas girando las ruedas de derecha a izquierda y empezando por la rueda de la extrema derecha, hallar una de las combinaciones correctas para la cerradura será exponencialmente más difícil: uno esperaría encontrar la solución correcta para la rueda a la extrema derecha 
después de cinco intentos, pero la probabilidad de que ésta sea también la solución correcta para toda la cerradura es tan sólo de $1 / 10^{9}$, puesto que al hacer girar las ruedas de derecha a izquierda, cambiamos al azar lo que cuenta como la solución correcta para todas las ruedas que ya movimos y que se encuentran a la derecha de aquella que estamos moviendo en ese momento.

Wimsatt añade algunos otros detalles al diseño de esta cerradura antes de hacer la analogía con ciertos procesos de desarrollo ontogenético. Sin embargo, la presentación anterior es suficiente para nuestros propósitos. La analogía con la ontogénesis se puede apreciar si hacemos corresponder las ruedas giratorias de la cerradura con las diferentes etapas del desarrollo ontogenético de un organismo, donde la etapa más temprana corresponderá a la rueda situada en la extrema izquierda, y las etapas subsiguientes a las ruedas localizadas progresivamente a la derecha. Además, no se hablará de la o las combinaciones correctas para la cerradura, sino de las soluciones adaptativas para el organismo. Como veremos, la analogía nos permite conceptuar de maneras teóricamente muy fértiles muchas de las características y la estructura general de procesos de desarrollo y evolutivos.

Por ejemplo, así como es más probable que un cambio azaroso en la posición de una de las ruedas en la extrema izquierda de la cerradura provoque a su vez más cambios en las soluciones que contarán como correctas en más ruedas a la derecha de aquella rueda, así también es más probable que una mutación que ocurra en una etapa más temprana del desarrollo provoque mayores desajustes en el desarrollo posterior; en palabras de Wimsatt: "la probabilidad de que una mutación en una etapa [temprana] permita un desarrollo normal más adelante ¡declina exponencialmente!" (Wimsatt, 1986, p. 195; la traducción es mía).

Adicionalmente, la idea de que, en la cerradura, la solución correcta para cada rueda está determinada por las posiciones (correctas o no) de todas las ruedas a la izquierda de aquélla corresponde al hecho de que los rasgos que aparecen en las 
etapas tardías del desarrollo ontogenético "apropiado" de un organismo normalmente dependen de la ocurrencia de ciertos rasgos específicos en etapas más tempranas. Sin embargo, de entre los rasgos que aparecen en una determinada etapa del desarrollo, hay algunos de cuya aparición dependen más rasgos, y para conceptuar esta característica estructural del desarrollo, Wimsatt hablará de los diferentes grados de atrincheramiento generativo de los diferentes rasgos que surgen durante el desarrollo ontogenético de un organismo: "Por lo tanto, diré que ciertos rasgos están 'atrincherados generativamente' en la medida en que existe cierta cantidad de rasgos que se desarrollan más adelante y que dependen de aquellos" (Wimsatt, 1986, p. 198; la traducción es mía).

Así, se puede decir que, para Wimsatt,

a. Un rasgo $T$ está generativamente atrincherado en un organismo $O$ en grado $n$ cuando $O$ tiene $T$ y un número $n$ de otros rasgos $(n \geq 1)$ tales que $T$ fue un factor causal importante ${ }^{20}$ en la aparición de todos estos otros rasgos durante el desarrollo ontogenético de $O$.

Sin embargo, esta caracterización del atrincheramiento requiere aún mayor precisión ya que, como hemos repetido ad náuseam, el desarrollo de un organismo determinado puede tomar muchas y diversas direcciones dependiendo de los factores ambientales (tanto "internos" como "externos") presentes durante el mismo - y sólo algunas de estas direcciones contarán como "apropiadas" o "normales" o "típicas". Además, con frecuencia un ambiente "apropiado" en una etapa temprana del desarrollo de un organismo difiere sustancialmente del ambiente apropiado para una etapa posterior. Tomando en cuenta todas estas consideraciones, se puede reformular la caracterización anterior de atrincheramiento de la siguiente manera:

b. Un rasgo $T$ está generativamente atrincherado en un organismo $O$ en grado $n$ cuando $O$ tiene $T$ y un número $n$

${ }^{20}$ Digo "un factor causal importante" para descartar factores causales que son meros disparadores de ciertos procesos, es decir, disparadores que determinan únicamente el tiempo en el que ocurren o empiezan a ocurrir. 
de otros rasgos $(n \geq 1)$ tales que $T$ fue un factor causal importante en la aparición de todos estos otros rasgos durante el desarrollo ontogenético de $O$ y tal desarrollo tuvo lugar en ciertos medios ambientes apropiados.

El problema aquí tiene que ver con la caracterización de la noción de un ambiente apropiado. No puede decirse que los medios ambientes apropiados en relación con el desarrollo de $O$ son aquellos en los cuales los miembros de la especie de $O$ desarrollan los rasgos fenotípicos que son "normales" o típicos de esa especie, ya que esto presupone que no hay una variedad fenotípica sustancial dentro de las especies biológicas, lo cual es simplemente falso. Por otra parte, la correspondencia que, en su analogía, Wimsatt establece entre "solución correcta para una rueda giratoria" y "solución adaptativa para un organismo" sugiere que la noción que él tiene en mente es algo como lo siguiente: los medios ambientes apropiados para un organismo son aquellos que contribuyeron causalmente al desarrollo de ciertos rasgos en $\mathrm{O}$ que son adaptativos. Si esto es así, entonces la caracterización anterior del atrincheramiento generativo puede reformularse como sigue:

c. Un rasgo $T$ está generativamente atrincherado en un organismo $O$ en grado $n$ cuando $O$ tiene $T$ y un número $n$ de otros rasgos $T_{1}, \ldots, T_{n}(n \geq 1)$ tales que $T$ fue un factor causal importante en la aparición de $T_{1}, \ldots, T_{n}$, los cuales cumplen con las siguientes condiciones: (i) $T_{1}$, $\ldots, T_{n}$ aparecieron durante el desarrollo ontogenético de $O$, y (ii) $T_{1}, \ldots, T_{n}$ son adaptativos en el ambiente en el que $O$ de hecho vive.

Pero no creo que esto sea lo que Wimsatt tiene en mente, puesto que un organismo de una especie determinada puede actualmente vivir en medios ambientes que son (estadística y filogenéticamente) muy atípicos de esa especie - lo que significaría que cierto rasgo de un organismo podría considerarse como si estuviera generativamente atrincherado en ese organismo cuando ese rasgo fuese un factor causal importante en la 
aparición de otros rasgos en ese organismo durante su desarrollo ontogenético, y cuando estos otros rasgos fuesen adaptativos en algún ambiente, sin importar lo artificial o atípico que fuese este ambiente. Por el contrario, para Wimsatt, la idea del atrincheramiento generativo es la de permitir conceptuar ciertos aspectos del desarrollo ontogenético de organismos biológicos en términos de algunos aspectos de la historia evolutiva de esos organismos. Si esto es así, entonces es posible que nuestra caracterización de los factores ambientales típicos de una población ayude a Wimsatt a precisar su noción de atrincheramiento generativo. Recordemos que, en nuestra propuesta, un factor causal ambiental es típico de una población si es causalmente necesario en la producción de un rasgo fenotípico que ha probado ser adaptativo en la historia evolutiva de esa población. De la caracterización de atrincheramiento propuesta por Wimsatt y de la que yo sugiero se obtiene la siguiente:

d. Un rasgo $T$ está generativamente atrincherado en un organismo $O$ en grado $n$ cuando $O$ tiene $T$ y un número $n$ de otros rasgos $T_{1}, \ldots, T_{n}(n \geq 1)$ tales que $T$ fue un factor causal importante en la aparición de $T_{1}, \ldots, T_{n}$ durante el desarrollo ontogenético de $O$ que tuvo lugar en aquellos medios ambientes que incluyen todos los factores causales ambientales típicos de la población a la que $O$ pertenece con respecto a los rasgos $T_{1}, \ldots, T_{n}$ (los cuales, en consecuencia, fueron adaptativos en algún ambiente ancestral).

Es importante notar que Wimsatt considera que su noción de atrincheramiento se aplica no únicamente a lo que se suele pensar que son los "rasgos fenotípicos" de los organismos, sino también a las condiciones o rasgos de lo que tradicionalmente se ha considerado como el "ambiente" — es decir, las condiciones "externas" a los organismos. Wimsatt dice:

De acuerdo con esta concepción, queda muy claro que la información adquirida del ambiente puede tener un efecto profundo, si está atrincherada generativamente y a profundidad en relación con la conducta subsiguiente; según este análisis, si está atrincherada 
generativamente, es innata. (Wimsatt, 1986, p. 200; las cursivas y la traducción son mías.)

Así, Wimsatt acepta que algunos factores ambientales (en el sentido tradicional de 'ambiente', entendido como algo externo al organismo) pueden estar generativamente atrincherados (y, por ende, ser innatos) en un organismo $O$ con respecto a un rasgo o constelación de rasgos fenotípicos de $O$ siempre y cuando tales factores ambientales sean factores causales importantes en la generación de otros rasgos de $O$ que han probado tener un valor adaptativo en la historia evolutiva de la población a la que $O$ pertenece. Así, la siguiente es una última precisión de la noción wimsattiana de atrincheramiento:

e. Un rasgo $T$ está generativamente atrincherado en un organismo $O$ en grado $n$ si y sólo si $O$ tiene un número $n$ de otros rasgos $T_{1}, \ldots, T_{n}(n \geq 1)$ tales que $T$ fue un factor causal importante en la aparición de $T_{1}, \ldots, T_{n}$ durante el desarrollo ontogenético de $O$ que tuvo lugar en aquellos medios ambientes que incluyen todos los factores causales ambientales típicos de la población a la que $O$ pertenece con respecto a los rasgos $T_{1}, \ldots, T_{n}$ (los cuales, en consecuencia, fueron adaptativos en algún ambiente ancestral).

Adicionalmente, al caracterizar lo innato en términos de la noción de atrincheramiento generativo, Wimsatt parece dispuesto a aceptar sin titubeos que su propuesta constituye una "una cirugía radical en la distinción innato-adquirido [...] y un argumento en favor de la eliminación de la vieja distinción" (Wimsatt, 1986, p. 186; la traducción es mía).

Lo que Wimsatt hace es proponer una nueva distinción que, según él, preserva lo bueno y descarta lo malo de la vieja. Ciertamente, lo que él propone es una cirugía radical de uno de los viejos conceptos causales de lo innato - tan radical que el nuevo concepto en poco se parece al original. Veamos:

Primero, hay que notar que la caracterización de Wimsatt de lo innato es demasiado amplia relativa a la manera en que el término innato se usa en las disciplinas en cuestión; como ya 
vimos, Wimsatt está dispuesto a afirmar que buena parte del ambiente externo en el que se desarrollan la mayoría de los organismos biológicos resultaría ser innata a esos organismos $-\mathrm{y}$ los estudiosos en las disciplinas cognitivas antes mencionadas nunca afirman que, por ejemplo, la temperatura en la que se desarrolla un organismo sea innata a ese organismo, aun cuando se conceda que pueda estar generativamente muy atrincherada en su desarrollo.

Por otra parte, la caracterización de lo innato en Wimsatt es también demasiado estrecha, pues, según él, resultaría que ninguno de aquellos rasgos de los organismos biológicos que son o fueron adaptativos y que tienen un componente genético pero que no son ya en sí mismos factores causales en la aparición de otros rasgos fenotípicos adaptativos durante el desarrollo ontogenético - puesto que son, por ejemplo, los productos fenotípicos finales de diferentes cascadas regulatorias - contaría como innato. Por ejemplo, según Wimsatt, es probable que la capacidad general de recordar o la forma y disposición del pulgar en los humanos probablemente no sean innatos, lo cual, de nuevo, choca con la manera en la que se usa el término 'innato' en las ciencias cognitivas aquí consideradas, ya que con frecuencia se dice que determinado rasgo cognitivo de un organismo - por ejemplo, un mecanismo cognitivo de cierto tipo- puede ser tan innato como cualquier otro rasgo fenotípico innato, aun cuando ese rasgo cognitivo no tenga ningún efecto fenotípico adaptativo o tenga muy pocos. ${ }^{21}$

Quiero precisar muy claramente el alcance de las observaciones anteriores; es decir, lo que creo que muestran. Ciertamente no muestran que la noción wimsattiana del atrincheramiento generativo no sea interesante, o que no tenga ninguna utilidad en la biología evolutiva y la del desarrollo. Todo lo contrario, es una propuesta muy interesante que permite teorizar de maneras muy fértiles algunos aspectos importantes del desarrollo en el marco de una biología evolucionista. Por otra parte, una caracterización de lo innato que se acerque más que la de Wimsatt

${ }^{21}$ También André Ariew expresa esto como una objeción seria contra la caracterización wimsattiana de lo innato. Véase Ariew 1999, pp. 135-136. 
a por lo menos algunas de las connotaciones centrales asociadas al concepto tal y como se usa en algunos contextos científicos sería ceteris paribus preferible. Si esto es correcto, por un lado tendríamos el concepto de atrincheramiento generativo (distinto del de lo innato) para conceptuar algunos aspectos cruciales del desarrollo en un marco evolutivo y, por otro, un concepto de lo innato como el propuesto en la sección anterior de este artículo - un concepto que, como se vio, caracteriza los rasgos innatos como aquellos que han probado tener un cierto valor adaptativo, y que surgen durante el desarrollo ontogenético de los organismos como resultado de ciertos tipos de factores ambientales y de factores genéticos.

Sin embargo, en la sección anterior también expresé algunas reservas serias respecto al uso de la palabra "innato" en este sentido - reservas que sigo sosteniendo. De hecho, me inclino más a descartar del todo la palabra 'innato' en el ámbito de la biología - y de la psicología. A fin de cuentas, la palabra 'innato' - a diferencia de la palabra "herencia" — no es un término técnico en ninguna rama de la biología contemporánea. Propongo entonces que la noción de atrincheramiento generativo se entienda como una noción que permite conceptuar un aspecto importante del desarrollo a la luz de la biología evolutiva, y que la noción articulada en la sección anterior se entienda más bien como un intento inicial de explicación sistemática, a la luz de la biología del desarrollo, de por lo menos parte del concepto de rasgo fenotípico heredado que ya se usa en la biología evolutiva, i.e.:

Un rasgo $T$ de un organismo perteneciente a una población determinada de una especie es heredado cuando:

a) El organismo en cuestión posee $T$, y

b) $T$ apareció en ese organismo como resultado de su desarrollo ontogenético en un ambiente que incluye todos los factores causales ambientales típicos de esa población con respecto al rasgo $T$ en $t$, y como resultado de factores genéticos. 
Se dice que un factor causal ambiental es típico de una población relativo a un rasgo fenotípico $T$ cuando $T$ ha probado ser un rasgo adaptativo para los miembros de esa población y el factor ambiental en cuestión (ya sea "interno" o "externo") es causalmente necesario para la aparición de $T$ en los miembros de esa población durante su historia evolutiva.

Ahora bien, las dos nociones antes examinadas - la de atrincheramiento y la de lo heredado - están íntimamente relacionadas. Por ejemplo, si un rasgo fenotípico $T$ de un organismo $O$ es heredado, entonces todos los factores causales ambientales (internos y externos) típicos de la población a la que $O$ pertenece - al igual que los factores genéticos-, que fueron responsables de la aparición de $T$ en $O$ durante su desarrollo, estarán generativamente atrincherados en $O$ - puesto que $T$ es un rasgo adaptativo. De manera similar, si un rasgo fenotípico $T$ de $O$ está generativamente atrincherado en $O$, entonces hay ciertos rasgos en $O$ que aparecieron durante su desarrollo ontogenético que son heredados siempre y cuando $T$ haya sido un factor causal de su aparición junto con otros factores causales atrincherados en $O$, entre los cuales se incluyen ciertos factores genéticos.

Veremos ahora que la noción aquí propuesta de rasgo heredado también puede explicar algunas de las intuiciones asociadas a lo innato que, según Wimsatt, su noción de atrincheramiento logra explicar. La primera afirma lo siguiente:

La conducta innata es relativamente resistente al cambio evolutivo.

Si en vez de 'innata' ponemos 'heredada', esta afirmación es plausible; puesto que, si la conducta en cuestión es heredada, entonces es adaptativa y es el resultado de factores causales que están más o menos atrincherados en el organismo en cuestión, lo cual significa (recordemos la analogía con la cerradura del desarrollo) que es improbable que un cambio en esos factores causales dé como resultado un desarrollo posterior normal y un organismo viable.

La segunda intuición que nuestra caracterización de lo heredado explica es la siguiente: 
Si ciertos rasgos innatos no aparecen durante el desarrollo, defectos funcionales importantes se presentarán.

Si un rasgo es heredado (en nuestro sentido), entonces es adaptativo y se debe a factores causales generativamente atrincherados - que, cuanto más atrincherados estén, menos probable será que, en su ausencia, el desarrollo posterior sea normal y dé como resultado un organismo viable. Ahora bien, si un rasgo heredado no aparece durante el desarrollo, entonces es probable que algunos de los factores causales típicamente responsables de la aparición de ese rasgo no hayan estado presentes, factores causales atrincherados en el organismo en cuestión - y, entre más atrincherados estén estos factores en ese organismo, más probable será que el resultado final del desarrollo incluya defectos funcionales importantes. Ergo, el que aparezcan algunos defectos funcionales importantes durante el desarrollo es un indicio de que algunos de los rasgos causalmente coasociados a los factores causales cuya ausencia redundó en aquellos defectos son innatos.

\section{Conclusiones}

Examiné dos conceptos causales internistas de lo innato; es decir, conceptos que caracterizan lo innato como los rasgos de un organismo que son resultado exclusivamente de causas "internas" al organismo. Argumenté que estos conceptos son inaceptables puesto que la existencia de rasgos fenotípicos en organismos multicelulares de suficiente complejidad surgidos durante el desarrollo ontogenético de tales organismos exclusivamente como resultado de factores causales "internos" es improbable.

Por otra parte examiné dos conceptos causales externistas de lo innato que proponen que un rasgo es innato cuando es resultado de factores causales genéticos e internos y de algunos factores "externos", siempre y cuando estos últimos sean factores ambientales "típicos" de la población o de la especie relevante. Exploré las dos maneras respectivas de caracterizar una noción de factor ambiental típico. Rechacé la primera - y su correspondiente noción de lo innato-, puesto que presuponía que todos los medios ambientes en que viven todos los 
miembros de una especie comparten por lo menos algunos rasgos importantes.

La segunda caracterización externista de lo innato que he examinado - la cual también caracteriza lo innato como aquello que es resultado de factores causales genéticos e internos y de algunos factores externos "típicos" de la población relevantese propone como una caracterización más precisa de la noción de un rasgo fenotípico heredado, y no como una explicación de lo innato.

Finalmente presenté y examiné una explicación de lo innato propuesta por Wimsatt. La idea es que un rasgo innato es el que desempeña un papel causal importante en la generación de muchos otros rasgos de $O$ (durante su desarrollo ontogenético), rasgos que han probado tener importantes ventajas evolutivas. El rasgo, entonces, está "atrincherado" en el sentido de que es muy probable que un cambio en tal rasgo - o su desaparicióntenga consecuencias causales muy serias para el desarrollo ontogenético de $O$. Argumenté que, aunque esta noción goza de un interés intrínseco y de una gran fertilidad teórica en la biología, hay un serio riesgo de equivocación si se la propone como una explicación de la noción de lo innato.

\section{BIBLIOGRAFÍA}

Ariew, A., 1999, "Innateness Is Canalization: In Defense of a Developmental Account of Innateness", en Valerie Gray Hardcastle (comp.), Where Biology Meets Psychology, MIT Press, Cambridge, Mass., pp. 117-138.

Elman, J.L. et al., 1996, Rethinking Innateness: A Connectionist Perspective on Development, MIT Press, Cambridge, Mass.

Gerhart, J. y M. Kirschner, 1997, Cells, Embryos and Evolution: Toward a Cellular and Developmental Understanding of Phenotypic Variation and Evolutionary Adaptability, Blackwell Science, Malden, Mass.

Griffiths, P.E. y R.D. Gray, 1994, "Developmental Systems and Evolutionary Explanation", Journal of Philosophy, vol. 91, pp. 277304. 
Hull, D., 1999, "On the Plurality of Species: Questioning the Party Line", en Robert A. Wilson (comp.), Species: New Interdisciplinary Essays, MIT Press, Cambridge, Mass., pp. 23-48.

Johnson, M. y J. Morton, 1991, Biology and Cognitive Development: The Case of Face Recognition, Blackwell, Oxford.

Kandel, E.R., J.H. Schwartz, y T.M. Jessell, 1995, Essentials of Neural Science and Behavior, Appleton and Lange, Stamford, Connecticut.

Newport, E.L., 1991, "Contrasting Conceptions of the Critical Period for Language", en Susan Carey y Rochel Gelman (comps.), The Epigenesis of Mind: Essays on Biology and Cognition, Lawrence Erlbaum Associates, Publishers, Hillsdale, Nueva Jersey, pp. 111130.

Shettleworth, S.J., 1998, Cognition, Evolution, and Behaviour, Oxford University Press, Oxford.

Tooby, J. y L. Cosmides, 1990, "On the Universality of Human Nature and the Uniqueness of the Individual: The Role of Genetics and Adaptation", Journal of Personality, vol. 58, pp. 17-67.

Wimsatt, W., 1986, "Developmental Constraints, Generative Entrenchment and the Innate-Acquired Distinction", en William Bechtel (comp.), Integrating Scientific Disciplines, Martinus Nijhoff Publishers, Dordrecht, Bechtel, pp. 185-208.

Recibido el 12 de marzo de 2003; revisado el 4 de septiembre de 2003; aceptado el 1 de octubre de 2003. 